\title{
DIVERSITY OF UNDERSTOREY VEGETATION IN THREE LOWLAND RAIN FORESTS IN SOUTHWEST OF SRI LANKA
}

\author{
U L S Sirisena and B M P Singhakumara \\ Department of Forestry \& Environmental Science \\ University of Sri Jayewardenepura
}

The study examined the diversity and composition of understorey vegetation in Sinharaja Man \& Biosphere forest reserve, Kanneliya forest reserve, and Oliyagankele forest reserve. The understorey vegetation was sampled in 54, 27, and 27 plots in Sinharaja FR, Kanneliya FR, and Oliyagankele FR respectively each $5 \mathrm{~m} \times 5 \mathrm{~m}$. Ecological indices and important value index, which is the expression of the dominance of particular species in different habitats, were calculated.

The diversity index (Shannon's) calculated for understorey species found in each plot enumerated at Sinharaja FR, Kanneliya FR, and Oliyagankele FR showed that that there is no significant difference in diversity among reserves except for slightly higher diversity observed in Kanneliya forest reserve. A total of 68,77, and 63 understorey species were found from Sinharaja, Kanneliya, and Oliyagankele FR respectively. There were 40 endemic understorey species in Sinharaja FR and in Kanneliya each, and 36 in Oliyagankele FR. There were 11,17 , and 14 understorey species found only from Sinharaja, Kanneliya and Oliyagankele FR respectively. The most common family in Sinharaja FR and Oliyagankele FR was the Euphorbiaceac, and Fabaceae was in Kanneliya FR. There were slight differences in species composition within each forest reserve from valley to ridge.

Results of this study shows that although the difference in diversity is not significant, there are differences in the composition of the understorey as the elevation and mean annual rainfall decreases from Sinharaja FR to Oliyagankele FR. This study also found that that are higher percentage of endemic in the understorey of all three study sites.

Proceedings of the Ninth Annual Forestry and Environment Symposium 2003 of the Department of Forestry and Environmental Science, University of Sri Jayewardenepura, Sri Lanka 